\title{
Trilogy of foregut, midgut and hindgut atresias presenting in reverse order
}

\author{
Ramnik V Patel, ${ }^{1,2}$ Paul Jackson, ${ }^{3}$ Paolo De Coppi, ${ }^{3}$ Agostino Pierro ${ }^{3}$
}

${ }^{1}$ Department of Paediatric Urology, University College London Hospitals NHS

Foundation Trust, London, UK ${ }^{2}$ Department of Paediatric Urology, Great Ormond Street Hospital for Children NHS Foundation Trust, London, UK ${ }^{3}$ Neonatal and Paediatric Surgery, GOSH and ICH, London, UK

\section{Correspondence to} Ramnik V Patel, ramnik@doctors.org.uk

Accepted 16 April 2014

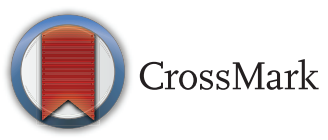

To cite: Patel RV, Jackson $P$, De Coppi $P$, et al. BMJ Case Rep Published online:

[please include Day Month Year] doi:10.1136/bcr-2014204171

\section{SUMMARY}

We present a case of triple gut atresias (foregut, midgut and hindgut) with multiple congenital anomalies presenting as imperforate anus. Abdominal radiography showed the double bubble sign. Upper gastrointestinal study through a nasogastric tube confirmed duodenal obstruction. Exploratory laparotomy, duodenoduodenostomy for duodenal atresia and a left descending colostomy for anorectal malformation were performed. During extubation, the nasogastric tube came out and could not be reinserted by the anaesthetic team under laryngoscopic guidance. A chest radiograph showed the tube curled in the upper pouch. Bronchoscopy and oesophagoscopy confirmed oesophageal atresia (OA) with a distal

tracheoesophageal fistula (TOF). The patient underwent right-sided extrapleural thoracotomy and division of the fistula with primary repair of OA uneventfully. Triple gut atresias presenting in reverse order with multiple anomalies is rare and passage of a nasogastric tube into the stomach in the presence of OA+TOF is exceptional. Alimentary tract obstruction should be corrected in proximal to distal direction.

\section{BACKGROUND}

A trilogy of gut atresias involving all three embryological segments of the alimentary tract in the same patient associated with multiple congenital anomalies but no chromosomal or genetic abnormalities is very rare. ${ }^{1}$ We report such an exceptional case which presented in reverse order and also had an exceptional nasogastric passage to the stomach delaying the diagnosis and treatment of oesophageal atresia (OA) and tracheoesophageal fistula (TOF). ${ }^{2-4}$

\section{CASE PRESENTATION}

A term baby girl had been born by elective lower segment caesarean section for breech presentation. Multiple abnormalities had been detected antenatally. These were hydrocephalus, phocomelia with oligodactyly, atrio-ventricular septal defect (AVSD) and intra-uterine growth retardation.

The baby was born in good condition, was cardiovascularly stable and breathing in air. Meconium-stained liquor was noted at delivery but no meconium was noted to be passed following delivery. She did not pass meconium in the first $24 \mathrm{~h}$ and no anal opening could be seen in the perineum but urethral and vaginal openings appeared normal.

The baby had excessive salivation and some frothing, so an associated OA with a TOF was suspected. With some difficulty an attempt was made to pass a nasogastric tube into the stomach and the radiograph confirmed it was in the abdomen in the region of the stomach. However, there was a double bubble appearance with a possibility of duodenal atresia or associated malrotation and midgut volvulus so the patient was urgently referred to us after stabilisation.

The patient was referred to the paediatric surgical team as having an imperforate anus with a possible rectovestibular fistula, and transferred from the district general hospital. On examination, she had a urethral orifice and a vestibular orifice but no separate anus. The abdomen was soft, non-tender and scaphoid with epigastric fullness, but no mass was palpable.

\section{INVESTIGATIONS}

Chest and abdominal radiographs showed a small amount of gas in the stomach but no gas in the rest of the gastrointestinal tract (figure 1). It was unclear whether this was an atresia or a malrotation/volvulus. An upper gastrointestinal contrast study under fluoroscopy was suggestive of a possible midgut malrotation and volvulus (figure 2). A cranial ultrasound scan showed lobar holoprosencephaly and an abdominal ultrasound scan showed bilateral small dysplastic kidneys. An echocardiogram was performed which showed a complete AVSD with an additional secundum atrial septal defect. There was a moderate sized ventricular septal defect with a dilated coronary sinus.

Other abnormalities were as follows: microtia with absent external auditory meatus, complete AVSD, OA, TOF, duodenal atresia, anal atresia, bilateral radial ray abnormalities with oligodactyly, crowded mid-face features, and bilateral radial clubbing of the hands with only three digits.

A genetics review was performed by the clinical genetics team. The infant was the second child of consanguineous, Bangladeshi parents. Multiple congenital abnormalities identified in pregnancy were consistent with a diagnosis of trisomy 18 . However this constellation of syndromes would also fit a VACTERL-D association. Therefore, an urgent fluorescence in situ hybridization (FISH) study for chromosome 18 trisomy was performed which was normal.

\section{DIFFERENTIAL DIAGNOSIS}

Anorectal malformation with a rectovaginal fistula with either duodenal atresia or midgut malrotation with volvulus neonatorum with multiple congenital anomalies with a possible VACTERL-D association 
Figure 1 Chest and abdominal radiographs. Note the nasogastric tube (NGT), proximal pouch shadow and small gastric air bubble with the rest of the abdomen gasless.

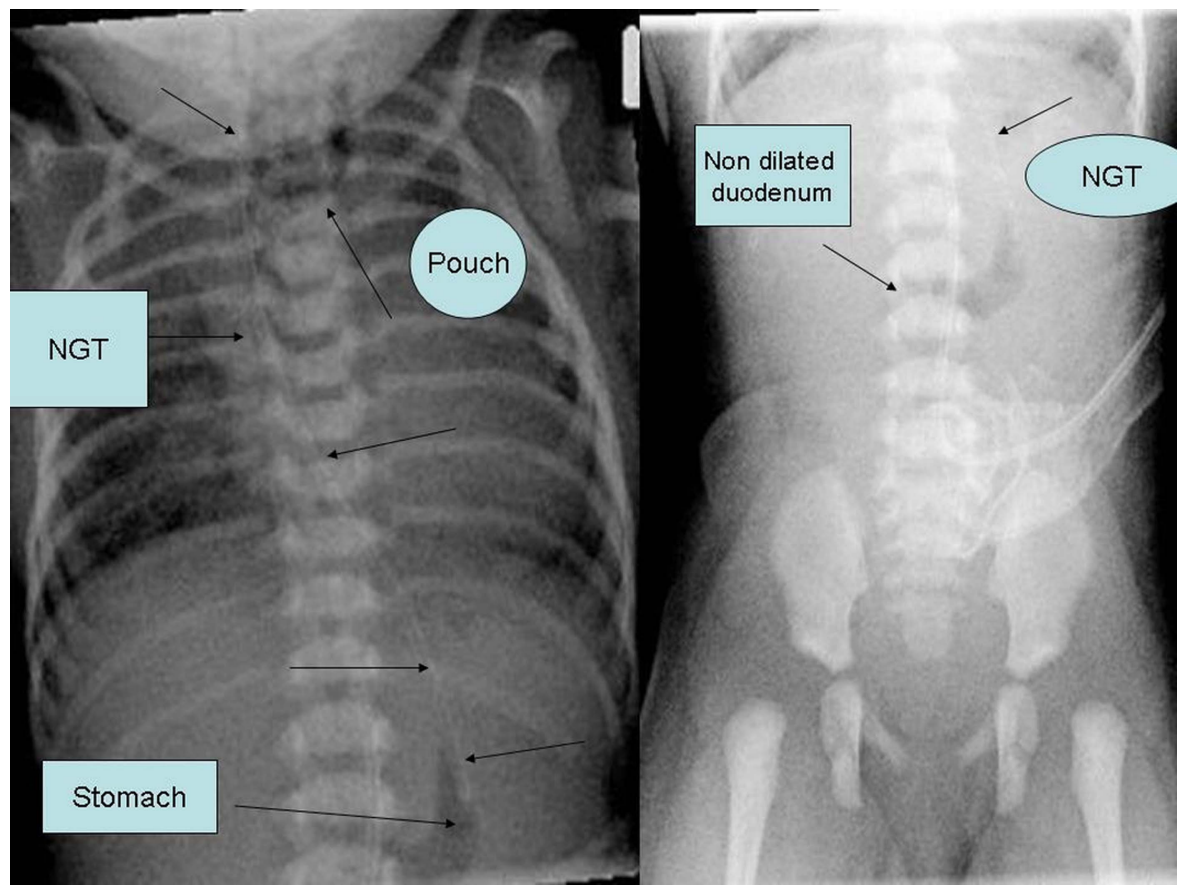

was considered. The possibility of chromosomal anomaly of trisomy 18 and the Martinez-Frias syndrome were considered before the clinical genetic team review and investigations.

\section{TREATMENT}

Following investigations and resuscitation, the patient underwent an exploratory laparotomy, a duodeno-duodenostomy for duodenal atresia and a left descending colostomy for anorectal malformation. During extubation, the nasogastric tube came out and could not be reinserted even by the anaesthetic team under laryngoscopic guidance. Chest radiograph showed the tube curled in the upper pouch. Bronchoscopy and oesophagoscopy confirmed OA with distal TOF. The patient underwent right-sided extrapleural thoracotomy, division of the fistula with primary repair of OA and a gastrostomy uneventfully.

\section{OUTCOME AND FOLLOW-UP}

The patient was transferred to the neonatal intensive care unit post-operatively. A number of discussions were held with her parents by consultants and the family liaison nurses. In summary, the infant had severe underlying abnormalities, multiple intestinal atresias, with a complete AVSD and holoprosencephaly. This constellation of abnormalities was considered incompatible with survival. Her parents understood the very poor prognosis in view of the multiple severe congenital anomalies involving all major body systems and the prospect of major

Figure 2 Upper gastrointestinal contrast study showing complete duodenal obstruction beyond the duodenal cap. NGT, nasogastric tube.

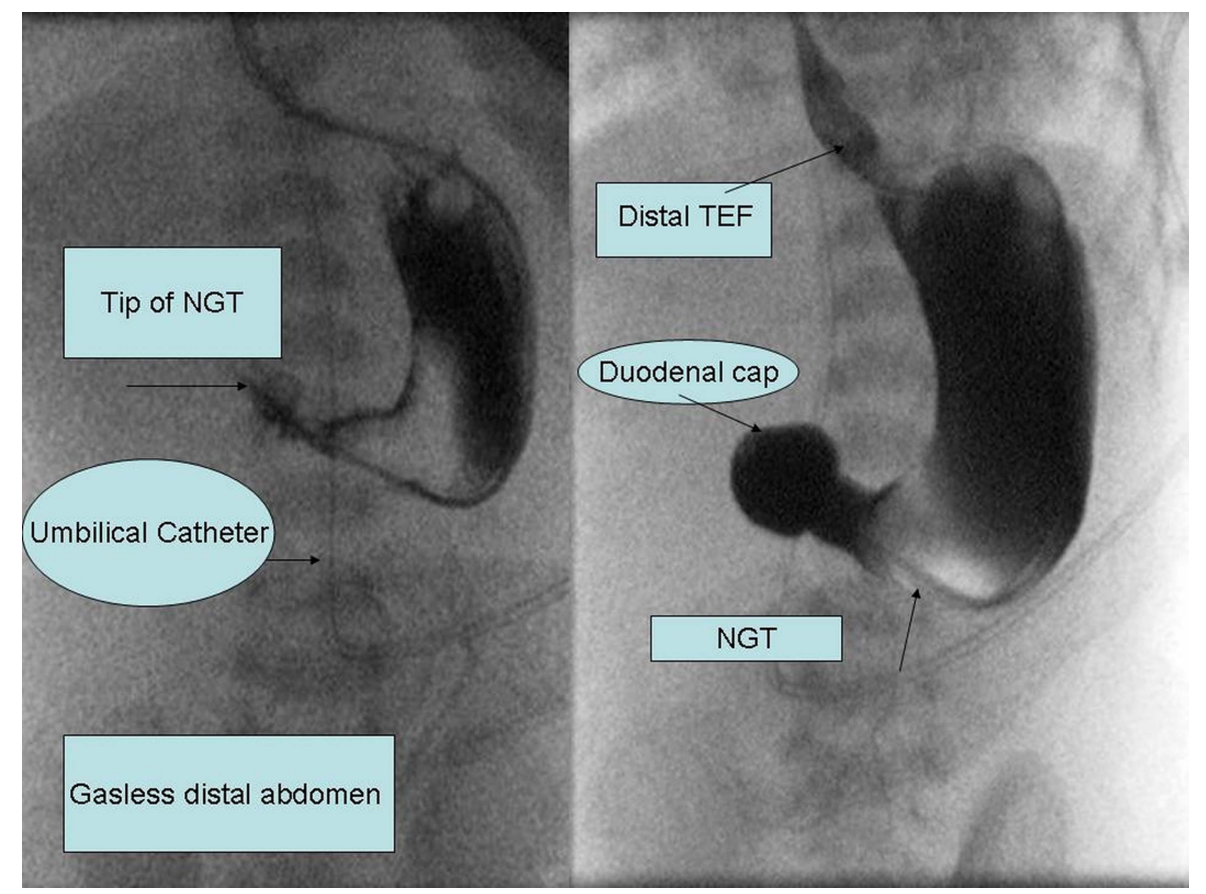


invasive recurrent surgery in order to attempt to address the infant's problems as listed above. It was felt that withdrawal of intensive care treatment would be in her best interests. Therefore, following family visits she was held in her mother's arms, the endotracheal tube was removed and death was pronounced. A death certificate was issued, with the cause of death as multiple congenital abnormalities (probably VACTERL) and multiple alimentary tract atresias (which were operated on, with the infant recovering from anaesthesia). The staff extended their deepest sympathy to her parents at this most difficult time and offered an appointment for bereavement follow-up in the future.

\section{DISCUSSION}

Alimentary tract atresias involving the foregut, midgut and hindgut in the same patient are very rare and it is presumed that the embryopathogenesis of each is different. Various mechanisms proposed for these atresias include differential growth of the tracheal bud and the oesophageal tube, recanalisation of the duodenal lumen, and formation of the urogenital diaphragm and cloacal membrane at the hind gut, respectively. ${ }^{5}$

Antenatal diagnosis of OA and TOF and duodenal atresia is possible but these conditions were missed in our case although multiple other congenital anomalies were detected. Nor were these conditions suspected in the postnatal period as the nasogastric tube was not obstructed by the proximal oesophageal blind pouch and radiographs confirmed its position in the abdomen and not curled up in the upper pouch. Various plausible mechanisms explaining such an exceptional event have previously been considered by Patel et al. ${ }^{4}$

With duodenal atresia, the double bubble sign is very obvious with significant dilatation of the duodenum. However, if there is an associated $\mathrm{OA}+\mathrm{TOF}$, then the infant may not be able to swallow meconium directly into the stomach and the distal TOF may lower the pressure thereby preventing the stomach from significantly dilating, which may explain why the antenatal diagnosis was missed in this case.

Alimentary tract atresia can be an isolated anomaly, a chromosomal anomaly (most commonly a trisomy or the Martinez-Frias syndrome) or can present in the form of an association. VATER (vertebral, anorectal, tracheal, oesophageal and renal anomalies) association has been modified to VACTERL association with the addition of cardiac and limb anomalies, and we have amended it to VACTERL-D to incorporate duodenal obstruction due to atresia, stenosis, and malrotation or volvulus neonatorum to include the midgut in addition to the foregut and hindgut. ${ }^{6-8}$

Even with the advanced technology of the 21st century, there are limitations to antenatal diagnosis and postnatal treatment of multiple severe congenital anomalies. If all had been detected prenatally, the option of termination of pregnancy should have been given to the family if acceptable to them. The prognosis of numerous multisystem anomalies is poor with very reduced quality of life with both the family and society carrying the burden of the disease. Palliative care management avoids such a massive waste of resources and saves time, money, energy and ongoing distress for all parties including the patient.

In alimentary tract obstruction, the proximal obstruction should be corrected first. In our case, OA+TOF would have been treated first in order to manage the airway and breathing, followed by tracing the continuity of the lumen from the proximal to the distal direction and addressing the duodenal obstruction, and then colonic diversion for the anorectal malformation. ${ }^{6}$

\section{Learning points}

- Triple gut atresias presenting in reverse order (hind gut, midgut and then foregut) with multiple anomalies without genetic abnormality is rare.

- Triple gut atresias may be missed antenatally and postnatally, thus delaying diagnosis and management.

- Passage of a nasogastric tube into the stomach in the presence of oesophageal atresia and tracheoesophageal fistula is exceptional; a nasogastric tube in the stomach nearly always rules out these conditions.

- In the alimentary tract, obstruction should be corrected in the proximal to distal direction.

- VATER association was modified to VACTERL and we have added VACTERL-D to include a significant incidence of duodenal anomalies.

Acknowledgements We are grateful to the radiology team, neonatal intensive care team, anaesthesiology teams and neonatal surgical teams for their help and support during the diagnostic and therapeutic interventions and decision making in this case.

Contributors All authors have made substantial contributions to the conception and design of this paper, the literature search, the acquisition, analysis and interpretation of the data, drafting the article or revising it critically for important intellectual content, and final approval of the version to be published.

\section{Competing interests None.}

Patient consent Obtained.

Provenance and peer review Not commissioned; externally peer reviewed.

\section{REFERENCES}

1 Patel RV, Kumar H, More B, et al. Trilogy of foregut atresia without genetic abnormalityexception to the Martinez-Frias syndrome. BMJ Case Rep 2014. doi:10.1136/ bcr-2013-200477

2 Patel RV, Kumar $\mathrm{H}$, More B, et al. Situs inversus totalis (SIT), oesophageal atresia (OA) and tracheooesophageal fistula (TOF). BMJ Case Rep. Published Online 3 June 2013. doi:10.1136/bcr-2013-009955

3 Patel RV, Greene O, Motiwale S, et al. The combination of pure oesophageal atresia with an associated missed H-type tracheo-oesophageal fistula. BMJ Case Rep. Published Online 29 July 2013. doi:10.1136/bcr-2013-200198

4 Patel RV, Jackson PB, De Coppi P, et al. Exclusion of oesophageal atresia by passage of a nasogastric tube: an exception to the rule. BMJ Case Rep 2013. doi:10.1136/ bcr-2013-201175

5 Pamiejer CR, Hubbard AM, Coleman B, et al. Combined pure esophageal atresia duodenal atresia, biliary atresia, and pancreatic ductal atresia: prenatal diagnostic features and review of the literature. J Pediatric Surg 2000;35:745-7.

6 Ein SH, Palder SB, Filler RM. Babies with esophageal and duodenal atresia: a 30 year review of a multifaceted problem. J Pediatric Surg 2006;42:530-2.

7 Kwok IH, Grant HW, Menon P. Trilogy of gastrointestinal atresias: a case report and review of the literature. J Pediatr Surg 2011;46:2391-3.

8 Savran B, Kocak A, Karakus YT, et al. Association of duodenal and biliary atresias in Martinez-Frias Syndrome: a very rare case. J Pediatr Surg Case Reports 2013;1:60-4. 
Copyright 2014 BMJ Publishing Group. All rights reserved. For permission to reuse any of this content visit http://group.bmj.com/group/rights-licensing/permissions.

BMJ Case Report Fellows may re-use this article for personal use and teaching without any further permission.

Become a Fellow of BMJ Case Reports today and you can:

- Submit as many cases as you like

- Enjoy fast sympathetic peer review and rapid publication of accepted articles

- Access all the published articles

- Re-use any of the published material for personal use and teaching without further permission

For information on Institutional Fellowships contact consortiasales@bmjgroup.com

Visit casereports.bmj.com for more articles like this and to become a Fellow 